\title{
MICROBIAL FLORA AND FOOD BORNE PATHOGENS ON MINCED MEAT AND THEIR SUSCEPTIBILITY TO ANTIMICROB IAL AGENTS
}

\author{
Haimanot Tassew (BSc, MSc) ${ }^{1}$, Alemseged Abdissa (BSc, MSc) ${ }^{1}$, Getenet \\ Beyene $(\mathrm{BSc}, \mathrm{MSc}, \mathrm{PhD})^{1}$, Solomon Gebre-Selassie (MD, MSc) ${ }^{2}$
}

\begin{abstract}
BACKGROUND: Food-borne pathogens are the leading cause of illness and death in developing countries. Changes in eating habits, mass catering, unsafe food storage conditions and poor hygiene practices are major contributing factors to food associated illnesses. In Ethiopia, the widespread habit of raw beef consumption is potential cause for food borne illnesses. The present study aimed at investigating the microbial quality of meat available in common retail shops, restaurants and abattoir of Jim ma City and determining susceptibility pattern of bacterial isolates.
\end{abstract}

METHOD: A total of 165 samples from food establishments, butcher shops and a slaughter houses were processed and analyzed for the presence of indicator bacterial and potential food pathogens using standards methods. Antimicrobial susceptibility test was performed for Salmonella, Shigella and Staphylococcus aureus isolates using Kirby-Bauer disk diffusion method.

RESULTS: A total of 165 samples were collected from twenty four hotels and five butchers and an abattoir. Various food borne pathogens were isolated in 13 (43.3\%) and indicator organisms in 29 (96.7\%) out of the thirty food establishments (hotels, butchery and abattoir). Overall, ten different bacterial species were isolated which included, proteus spp 89 (53.9\%), E. coli 44 (26.6\%), Providencia spp 23 (13.9\%) Citrobacter spp 15(9\%), Pseudomonas spp 9 (5.5\%), Klebsiella spp 2 (1.2\%), Enterobacter spp 2 (1.2\%), Salmonella spp 2(1.2\%), and Shigella species $1(0.6 \%)$. Out of the 44 E. coli isolates $37(84 \%)$ were thermo tolerant E. coli and out of the gram positive organisms identified 20 (12.1\%) were Staphylococcus aureus isolates. From the two Salmonella isolates one was susceptible against all 12 tested antimicrobials, while the other to all the 11 except cephalexin. Shigella dysentery was resistant only to co-trimoxazole and tetracycline. Out of the 20 S. aureus isolates, $90 \%$ showed resistance to oxacillin, $85 \%$ to ampicillin, $65 \%$ to erythromycin, $60 \%$ to amoxicillin, $35 \%$ to streptomycin, and $20 \%$ to vancomycin and all isolates were sensitive to co-trimoxazole (100\%). In this study, 90\% (18/20) of the S. aureus isolates were Methicillin Resistant Staphylococcus aureus.

CONCLUSION: In this study high percentage of indicator organisms as well as food borne pathogens were identified, which shows unhygienic condition of handling and processing in the food establishments. Our data also confirmed the presence of resistant food pathogens; particularly Staphylococcus aureus isolates which are Methicillin Resistant Staphylococcus aureus and multidrug resistant that emphasizes close follow up in the utilization of antibiotics. Therefore, meat handlers and sellers should be educated on the adverse effect of lack of proper personal, environmental hygiene and sanitation. In addition, consumers should be made aware of the risk of consuming raw and inadequately cooked meat.

KEYWORDS: Food pathogens, Staphylococcus aureus, Minced meat

\section{INTRODUCTION}

Food-borne pathogens are the leading causes of illness and death in developing countries resulting in the lose of labor force which could have contributed in the economic growth (1). Changes in eating habits, mass catering, unsafe food storage conditions and poor hygiene practices are major contributing factors to food associated illnesses (2). Contaminated raw meat is one of the main sources of food-borne illnesses $(3,4)$. The risk of the transmission of zoonotic infections is also associated with contaminated meat. International food management agencies, especially the World Health Organization (WHO), the Food and Agriculture Organization (FAO) and the International Hazard Analysis Critical Control Point Alliance (HACCP) have already provided guidelines to member countries about safe handling procedures such as HACCP and Good Manufacturing Practices (GMPs).

\footnotetext{
${ }^{1}$ Department of Laboratory Sciences and Pathology, College of Public Health and Medical Sciences, Jimma University,

${ }^{2}$ Department of Microbiology, Immunology and Parasitological, Faculty of Medical Sciences, Addis Ababa University, Ethiopia
} 
In Ethiopia, the widespread habit of raw beef consumption is a potential cause for food borne illnesses besides, the common factors such as overcrowding, poverty, inadequate sanitary conditions, and poor general hygiene (5). Raw meat is available in open-air local retail shops without appropriate temperature control and this is purchased by households and also minced meat (Kitfo) is served at restaurants as raw, slightlycooked or well- cooked.

Meat processing at retail level is likely to contribute for the higher levels of contamination in minced beef as compared to carcasses (6). The presence of even small numbers of pathogens in carcass meat and edible offal may lead to heavy contamination of minced meat when it is cut into pieces; as more microorganis $\mathrm{ms}$ are added to the surfaces of exposed tis sue (7).

Previous studies conducted in Addis Ababa indicated the occurrence of pathogens including Salmonella in different food animals, meat and meat products. In addition, outbreaks of infections somehow related with poor hygiene and consumption of contaminated food were reported in Ethiopia (8) and some were caused by Salmonella and Shigella (6, 9). Moreover, antibiotic resistance levels are also elevated among food-borne pathogens such as Salmonella and Shigella $(8,10)$. Although, it is difficult to prove a direct role of drug resistance in bacteria contaminating food items with increased clinical cases of resistant infections, the presence of such bacteria in food items could play a role in the spread of antimicrobial resistance amongst foodborne pathogens (11).

Thus, adequate information should be gathered to develop an effective strategy to reduce the outbreak of food born illnesses and resistance burden in the community. This study therefore aimed at investigating the microbial quality of meat available in common retail shops, restaurants and abattoir of Jimma Town and to determine susceptibility pattern of bacterial isolates.

\section{MATERIALS AND METHODS}

This study involved randomly selected 24 hotels and 5 butcher shops and an abattoir in Jimma Town from April to August 2009. Approximately six samples were collected from each outlet. Accordingly, a total of 120 minced meat ('kitfo') samples from 24 food establishments were collected. Twelve environmental samples from the slaughter house were collected comprising surface swabs taken from $30 \mathrm{~cm} 2$ of the surface of meat-cutting equipment such as knives, wooden boards and weighing scales. In addition, 25 and 8 carcasses swab samples comprising an area of $100 \mathrm{~cm} 2$ lean meat were collected from the butcher shops and slaughter house, respectively. The samples were collected in a sterile container and immediately transported using ice box to the laboratory for bacteriological analysis. The 24 food establishments were categorized in to three (A, B, C) groups according to the standards set by the town municipality. A hotel in standard "A" fulfils: septic tank, waste pit, standard toilet (separate for male and female), standard kitchen, water tanker, medical checkup for workers every three months, clean kitchen utensils, standard bed room, and fire extinguisher. A hotel in standard " $\mathrm{B}$ " has all in "A" but lacks water tanker, medical checkup for workers every six months and no fire extinguisher; whereas, a standard " $\mathrm{C}$ " hotel has all defects seen in "B" and lacks septic tank, waste pit and has only one room toilet.

A $25 \mathrm{gm}$ sample of the minced meat was homogenized in $225 \mathrm{ml}$ of buffered peptone water (BPW) using homogenizer. The final homogenate gave a 1:10 dilution and was incubated for $24 \mathrm{hrs}$ at 350C. Out of this a serial dilution of 1:106, 1:107 and 1:108 was prepared and used for further analysis. All media and antibiotic discs were purchased from Oxoid, UK.

For is olation and identification of S. aureus a loop full of sample from the homogenate were inoculated on Manitol salt agar (MSA) and golden yellow colonies on MSA which were catalase positive and coagulase positive isolates were identified as $\mathrm{S}$. aureus. Next, the enriched sample was inoculated on MacConkey and xylose lysine deocycholate agar (XLD) and incubated at $37 \mathrm{oC}$ for 24 hours. For isolation and identification of Salmonella the following steps were followed. The sample was enriched on tetrathionate (TT) and Rappaport Vassiliadis (RV) broth selective media. Then the gram-negative organisms including Salmonella and Shigella were identified using a battery of biochemical tests like, reactions on Kligler's iron agar (KIA), lysine iron agar (LIA), urea, motility test, simmon's citrate, oxidase, indole and mannitol fermentation tests. To confirm thermo tolerant E. coli; suspected isolates were incubated at 440C water bath for 48 hours in nutrient broth and they were tested for growth at $440 \mathrm{C}$ and checked for indole production. Isolates which demonstrated growth at $440 \mathrm{C}$ with indole production were confirmed as thermotolerant E. coli. Furthermore, Salmonella and Shigella strains were sero-grouped by slide agglutination tests using poly $\mathrm{O}$ and single O-groups antisera (Remel, Eu rope Ltd, UK).

Antimicrobial susceptibility testing for Salmonella, Shigella and S. aureus was performed using the disk diffusion method and results were interpreted using the criteria of the National Committee for Clin ical Laboratory Standards (NCCLS, 2000). The

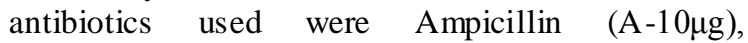
Amoxicillin/clavulanic acid (AM-10 $\mu$ g),

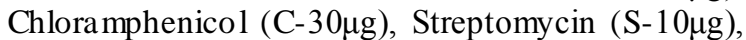




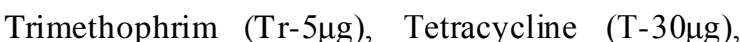
Ciprofloxacin $(\mathrm{Cf}-5 \mu \mathrm{g})$, Nalidixic acid $(\mathrm{Na}-30 \mu \mathrm{g})$,

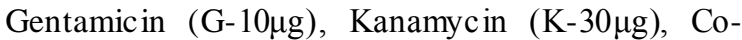

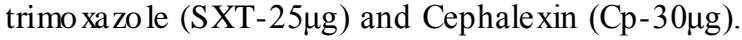
The criteria used to select the antimicrobial agents tested were based on the availability and frequency of prescription for the management of bacterial infections in Ethiopia. Antibiotic susceptibility testing for S. aureus was determined for Ampicillin $(\mathrm{A}-10 \mu \mathrm{g})$, A moxicillin/clavulanic acid (Am-10 $\mu \mathrm{g})$, Erythromycin (E-15 $\mu \mathrm{g})$, Oxacillin (Ox -1 $\mu \mathrm{g}$ ), Streptomycin(S-10 $\mu \mathrm{g})$, Co-trimoxazole (SXT-25 $\mu \mathrm{g})$ and Vancomycin (Va-30 $\mu \mathrm{g})$.

A standard reference strain of E. coli (ATCC 25922), sensitive to all antimic robial drugs was used as a quality control for disk diffusion.

Data obtained from this study was entered to computer, analy zed using SPSS for windows version 16.0 and interpreted. Ethical approval for the study was obtained from the Institutional Review Board (IRB) of Faculty of Medicine, Addis Ababa
University and from Jimma University Ethical Review Board.

'Indicator organisms' are defined as large group of bacteria including certain pathogenic bacteria, which are relatively easy to measure as a group and the presence of this in food, is likely to indicate the presence of pathogenic bacteria.

'Pathogenic bacteria' - bacteria that are known to cause infectious diseases in human.

\section{RES ULTS}

A total of 165 samples from 29 food establishments and a slaughter house were analyzed. Of the 30 establishments (24 hotels, 5 butcheries and an abattoir), various food borne pathogens in 13 $(43.3 \%)$ and indicator organisms in $29(96.7 \%)$ of them were isolated. Indicator organis ms were is olated from all the 5 butcheries and food pathogens from $3(60 \%)$ of them (Table 1$)$.

Table 1. Number of pathogenic and indicator organisms isolated from different food establishments, butcher shops, and abattoir in Jimma City, Southwest Ethiopia, 2009.

\begin{tabular}{llll}
\hline Sample source & $\begin{array}{l}\text { Food establishments } \\
\text { involved in the survey }\end{array}$ & $\begin{array}{l}\text { Food establishments positive for } \\
\text { pathogenic }\end{array}$ organis ms & $\begin{array}{l}\text { Food establishments positive } \\
\text { for indicator organis ms }\end{array}$ \\
\hline Hotels & & & \\
\multicolumn{1}{c}{ A } & 6 & $2(33 \%)$ & $6(100 \%)$ \\
B & 13 & $5(39 \%)$ & $12(92 \%)$ \\
C & 5 & $2(40 \%)$ & $5(100 \%)$ \\
Butcher shop & 5 & $3(60 \%)$ & $5(100 \%)$ \\
Abattoir & 1 & $1(100 \%)$ & $1(100 \%)$ \\
Total & 30 & $13(43.3 \%)$ & $29(96.7 \%)$ \\
\hline \multicolumn{2}{r}{ Key: A, B, Care food establishments categorized according to their standards set by the Jimma town municipality (see the result section). }
\end{tabular}

The only abattoir in Jimma Town was included in the survey and 20 samples were collected from various locations and meat processing instruments.
Out of these 20 samples, $4(20 \%)$ were found to have pathogenic organisms while $16(80 \%)$ carried indicator organisms (Table 2).

Table 2. Number of pathogenic and indicator organisms isolated from abattoir, Jimma Town, southwest Ethiopia, 2009.

\begin{tabular}{lclccc}
\hline Sample source & $\begin{array}{c}\text { Samples } \\
\text { collected }\end{array}$ & $\begin{array}{l}\text { Samples positive for } \\
\text { pathogenic organisms }\end{array}$ & $\begin{array}{c}\text { Samples positive } \\
\text { indicator organisms }\end{array}$ & for \\
\hline Carcasses & 8 & $1(12.5 \%)$ & $7(87.5 \%)$ \\
Knives swab & 8 & $3(38.0 \%)$ & $6(75.0 \%)$ \\
Floor swab & 4 & $0(0 \%)$ & $3(75.0 \%)$ \\
Total & 20 & $4(20.0 \%)$ & $16(80.0 \%)$ \\
\hline
\end{tabular}

Out of the 165 samples collected, ten different bacteria were isolated. Most of the isolates were members of the Entrobacteraeceae family including proteus spp 89 (53.9\%), E. coli 44 (26.6\%), Providencia spp 23 (13.9\%), Citrobacter spp 15(9\%), Pseudomonas spp 9 (5.5\%), Klebsiella spp $2(1.2 \%)$, Enterobacter spp 2 (1.2\%), Salmonella spp $2(1.2 \%)$, and Shige lla group-A $1(0.6 \%)$.
Out of the forty four E. coli isolates 37 (84\%) were thermo-tolerant E. coli. Of the gram positive organisms, identified $20 \quad(12.1 \%)$ were Staphylococcus aureus isolates (Figure 1). The two Salmonella isolates were in group A (isolated from minced meat) and group B (from the butcher's shop). 


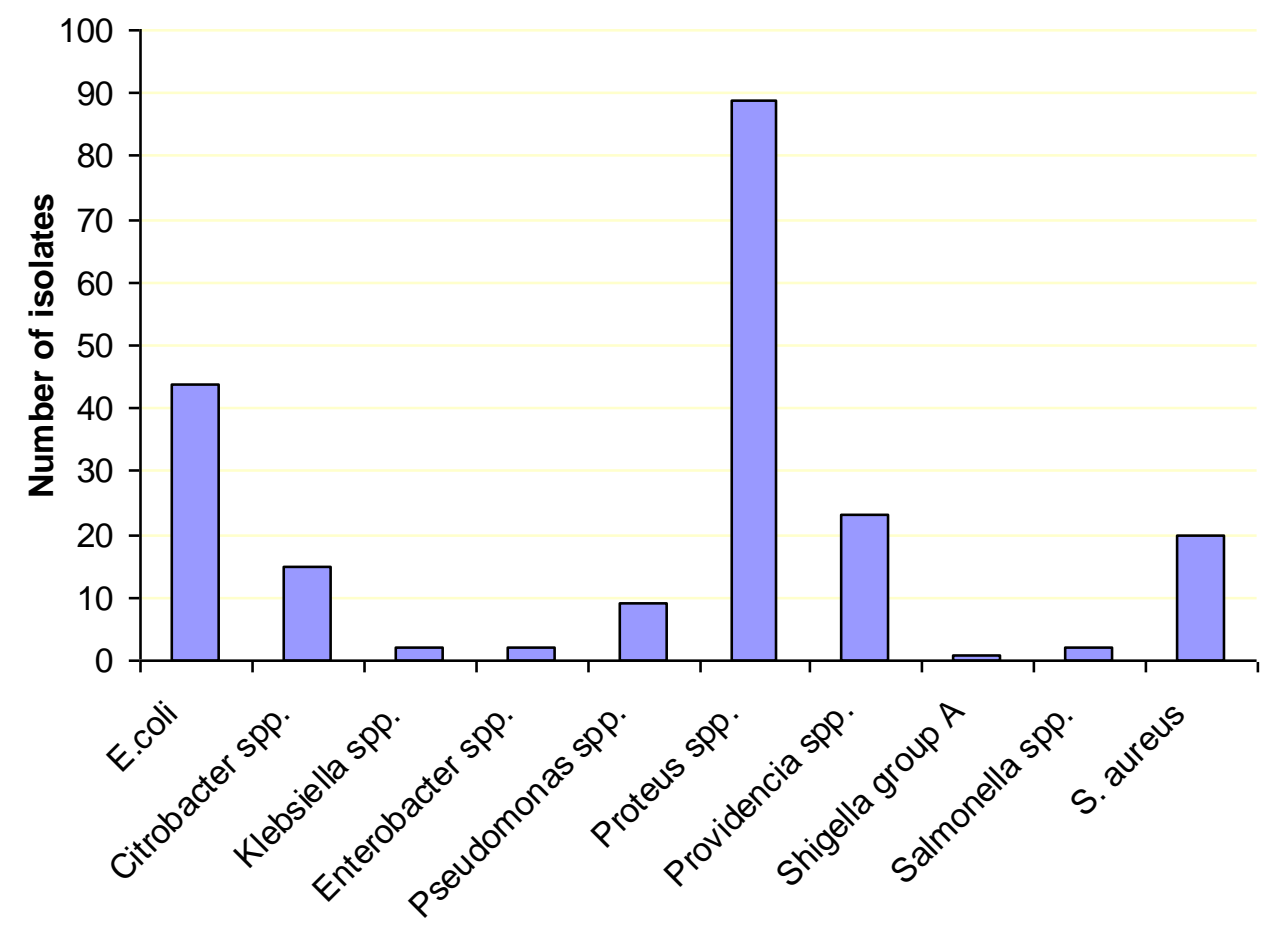

Bacterial isolates

Figure 1. Frequency distribution of bacterial isolates from samples (minced meat, unprocessed meat and from abattoir), Jimma town, southwest Ethiopia, April - August, 2009.

Of the two Salmonella isolates, group A was susceptible to all the 12 drugs whereas, group B was susceptible to the eleven tested drugs but resistant only to Cephalexin. The single Shigella isolate was susceptible for Ampicillin, Amoxicillin, Ciprofloxacin, Naldixic acid, Gentamicin, Kanamycin, Chloramphenicol and Cephalexin but resistant for Co-trimethoxazole, Tetracycline, Streptomycin and Trimethophrim.

A total of $20 \mathrm{~S}$. aureus isolates were tested for seven antibacterial agents which showed $90 \%$ were resistant to Oxacillin, $85 \%$ to Ampicillin, $65 \%$ to Erythromycin, $60 \%$ to Amoxicillin, $35 \%$ to streptomycin, and $20 \%$ to Vancomycin but all $(100 \%)$ of the isolates were sensitive to Cotrimoxazole. Eighteen of the $20(90 \%)$ S. aureus isolates were Methicillin Resistant Staphylococcus aureus (MRSA). However, 2(10\%) of the $20 \mathrm{~S}$. aureus isolates were sensitive to all antibiotics tested (Table 3).
The resistance pattern varied among five drugs and in general $\mathrm{S}$. aureus showed high level of resistance to Ampicillin, A moxicillin, Oxacillin, Erythromycin and Streptomycin. From the 18 organis ms tested 15 exhibited resistance to three or more antibiotics (Table 4).

Table 3. Resistance pattern of S. aureus, Jimma town, southwest Ethiopia, April - August, 2009.

\begin{tabular}{ll}
\hline Antimicrobials & $\begin{array}{l}\text { Resistant isolates } \\
\text { Number }(\%)\end{array}$ \\
\hline Ampicillin & $17(85)$ \\
Streptomycin & $7(35)$ \\
Amo xacillin & $12(60)$ \\
Erythromycin & $13(65)$ \\
Oxacillin & $18(90)$ \\
Vancomycin & $2(10)$ \\
Co-trimoxazo le & $0(0)$ \\
\hline
\end{tabular}


Table 4. Antibiogram of Staphylococcus aureus isolates from different food establishments, Jimma town, south west Ethiopia, 2009.

\begin{tabular}{lcc}
\hline \multicolumn{1}{c}{ Antibiotics } & No and \% resistant S. aureus \\
\hline & no & $\%$ \\
a & 1 & 5 \\
A, Ox & 1 & 5 \\
AM, E & 1 & 5 \\
A, E, Ox & 1 & 5 \\
A, Am, Ox & 1 & 5 \\
A, S, Ox & 1 & 5 \\
AM, Van, Ox & 2 & 10 \\
A, AM, E, Ox & 5 & 25 \\
A, E, S, Ox & 4 & 20 \\
A, AM, E, S, Ox & 1 & 5 \\
\hline Total & 18 & $90 \%$ \\
A $=$ Ampicillin, E = Erythromy cin, AM = Amoxicillin, S= Streptomycin, Ox = Oxacillin, Va = Vancomycin
\end{tabular}

\section{DISCUSS ION}

Food borne illnesses caused by non- typhoid Salmonella, S. aureus and E. coli represents a major public health problem worldwide. These pathogens are transmitted mainly through consumption of contaminated food and the presence of these organisms in meat animals and in raw meat products has relevant public health implications (12). In this study, it was found out that almost all of the food establishments had pathogenic and indicator bacteria. Similarly, pathogenic and indicator bacteria were isolated from one-fifth and four-fifth of the samples collected from the abattoir, respectively. This finding shows how high the magnitude of contamination at food establishments and at slaughter houses which may contribute to the incidence of food as sociated illnesses.

In this study, E. coli was isolated in the majority of food establishments, which indicates the presence of unhygienic food processing. Moreover, the identification of thermo-tolerant E. coli showed the presence of recent fecal contamination (13). This is in agreement with the study done in Trinidad meat processing plant where the isolation rate was $90 \%$ of E. coli from raw meat and $34.4 \%$ of E. coli from unprocessed ready-to-eat product (14). Similarly, a study in Tehran Restaurants $27(12.5 \%)$ E. coli were isolated from grilled ground meat (15). Naturally, high frequency of E. coli in minced meat shows high rate of contaminations during processing. Thus, E. coli's presence in minced meat might have originated from animal tissues or contaminated tools used in slaughtering and related treatment or cutting process. Although, serotyping of Escherichia coli is olates was not done in this study, isolation of these bacteria should be taken as a considerable threat (16).
As studies conducted elsewhere showed the importance of Proteus as an indicator of unhygienic food processing practice (17), the high frequency of Proteus species isolation observed in this study should be considered seriously. Proteus was also isolated from food sample and in stools of patients with gastroenteritis (18). Recently there was an outbreak report from Beijing which was attributed to contaminated food and Proteus mirabilis was identified as causative agent (19). Thus, the role of Proteus as food pathogen should be further investigated.

The identification of Providencie spp, Cirobacter spp and Pseudomonas spp in food in this study appears not to be a threat to public health, however, they could be opportunistic pathogens to immunocompromised and debilitated individuals (18). The identification of only two Salmonella isolates in this study is much lower than other reports where the isolation rate was $20 \%$ in Gaborone, Botswana $20 \%$ (20) and 9\% in Awasa, Ethiopia (21). Probably, low Salmonella detection could be due to the fact that Salmonella usually contaminates chicken and water than beef. The other factor may be the low prevalence of Salmonellosis in the Jimma community as recently has been reported (22).

The existence of Salmonella group A in minced meat indicates that the contamination is of human origin and result of poor personal hygiene during handling and processing of food. The presence of Salmonella group B indicates the contamination is from both sources for this group comprises many strains of Salmonella species (23). On ly one Shigella dysentery was isolated from the raw minced meat sample, similar to another report from Ethiopia which identified only 3(2\%) Shige lla spp. from 150 Macaroni samples studied (21).

The high prevalence rate $(12 \%)$ of Staphylococcus in unprocessed slices of meat and abattoir indicates 
the presence of cross contamination, which is usually related to human skin and clothing. As the carrier rate varies with different populations ranging from 10 to $40 \%$ in adults outside the hospital environment, Carriage may be intermittent or continuous over a long period of time. Approximately, $92 \%$ of people demonstrated nasal carriage of S. aureus in Jimma town (24) and this level of food contamination by this pathogen may lead to food intoxications. This pathogen is a major target in the screening of slaughterhouse carcasses to monitor hygienic conditions (25). Therefore, this study shows the slaughter house is unhygienic and needs close follow up to improve the situation.

In this study, one of the two Salmonella strains isolated has been found to be sensitive to all twelve antibiotics while the other showed resistance to only Cephalexin. This observation is comparable to study conducted in Addis Ababa which showed eight of the ten Salmonella isolates were sensitive to all ten drugs tested and the remaining two were resistant to Sulphadiazine (26).

The MRSA and multi drug resistant S. aureus in this study is higher than the one reported in a previous study in Jimma where 52\% MRSA and $72 \%$ of mu lti drug resistant (27). The presence of 90\% MRSA strain is demonstrating the fast growing and alarming situation to the public health system and the community. Thus, it requires strong controlling system of the personal hygiene and educating food handlers about the basic ideas of processing and producing a safe food.

In conclusion, the presence of food pathogens and indicator organisms such as thermo-tolerant E. coli in most of the food establishments shows poor food handling and processing practices. In addition, high proportion of methicillin resistant $\mathrm{S}$. aureus isolates indicate the importance of making periodic monitoring of food establishments. Therefore, meat handlers and sellers should be educated on the adverse effects of lack of proper personal, environmental hygiene and sanitation. In addition, consumers should avoid eating raw and inadequately cooked food.

\section{ACKNOWLEDGMENTS}

We acknowledge School of Graduate Studies, Addis Ababa University for financing the study.

\section{REFERENCES}

1. Fratamico PM, Bhunia AK, Smith JL. Foodborne Pathogens in Microbiology and Molecular Biology, Caister Academic Press, Wymondham, Norfolk, UK. 2005: 273.

2. Hedberg CW, Levine WC, White KE, Carlson RH, Winsor DK, Cameron DN, MacDonald
KL, Osterholm MT. An International foodborne Outbreak of Shigellosis Associated With a Commercial Airline. JAMA, 1992; 268: 32083212.

3. Bhandare SG, Sherikarv AT, Paturkar AM, Waskar VS, Zende RJ. A comparison of microbial contamination on sheep/goat carcasses in a modern Indian abattoir and traditional meat shops. Food Control, 2007; 18: 854-868.

4. Podpečan B, Pengov A, Vadnjal S. The source of contamination of ground meat for production of meat products with bacteria Staphylococcus aureus. Slov Vet Re,. 2007; 44: 25-30.

5. Siddiqui FJ, Rabbani F, Hasan R, Nizami SQ, Bhutta ZA. Typhoid fever in children: some epidemiological considerations from Karachi, Pakistan. Int J Infect Dis, 2006; 10: 215-222.

6. Tegegne M. and Ashenafi M. Microbial load and incidence of Salmonella species in 'kitfo', traditional Ethiopian spiced, minced meat dish. Ethiop J Health Dev, 1998; 12:135-140.

7. Ejeta G, Molla B, Alemayehu D and Muckle A. Salmonella serotypes isolated from minced meat beef, mutton and pork in Addis Ababa, Ethiopia. Revue Méd Vét, 2004;11:547-551.

8. Mache A., Mengistu Y. and Cowley S. : Salmonella serogroups identified from adult diarrheal out-patients in Addis Ababa, Ethiopia: Antibiotic resistance and plasmid profile analysis. East Afr Med J, 1997; 74:183-187.

9. Alemseged F, Yami A, Birke W, S/Mariam Z, Worku K. Investigation of Dysentry Outbreak and Its Causes, Jimma City Southwest, Ethiopia. Eth iop J Health Sci, 2009; 19(3): 147154.

10. Mache A. Salmonella serogroups and their antibiotic resistance patterns isolated from diarrhea stools of pediatric outpatients in Jimma Hospital and Jimma Health center, southwest Ethiopia. Ethiop J Health Sci, 2002; 12: 37-45.

11. Farzana, K., S. Akhtar and F. Jabeen. Prevalence and antibiotic resistance of bacteria in two ethnic milk based products. Pak J Bot, 2009; 41: 935-943.

12. Sousa CP. The Impact of Food Manufacturing Practices on Food borne Diseases. Braz arch biol Technol, 2008; 51(4):815-823.

13. Collee JG, Mackie TJ. Practical Medical Microbiology. Churchill livingstone. 14th ed: 1999: 883-884 and 898-907.

14. Gibbons IS, Adesiyun A, Seepersadsingh N, Rahaman. Investigation for possible source(s) of contamination of ready-to-eat meat products with Listeria spp. and other pathogens in a meat processing plant in Trinidad. Food Microbiol 2006; 23(4):359-66.

15. Tavakoli HR, Riazipou M. Microbial quality of cooked meat foods in Tehran University's Restaurants. Paki Med J, 2008; 24(4):595-599. 
16. Malicki A, Brużewicz S . Microbiological Status of Minced Meat Directly Post Production Is Influenced By Its Internal Temperature And $\mathrm{Ph}$ Value. Elect J Polish.,2005; 8 (Iss. 2):18.

17. Tambekar DH, Jaiswal VJ, Dhanorkar DV, Gulhane PB, Dudhane MN. Microbial Quality and Saftery of Street Vended Fruit Juices: A Case Study of Amravati City. Internet J Food Saf, 2009; 10: 72-76.

18. Riemann H P, Cliver DO. Food borne Infections And Intoxications, 3ed food Science Technol. Series. 2006: 348-358.

19. Wang Y, Zhang S, Yu J, Zhang H, Yuan Z, Sun Y, Zhang L. An outbreak of Proteus mirabilis food poisoning associated with eating stewed pork balls in brown sauce. Beijing Food Cont,2009; 21(3):302 -305.

20. Mrema N, Mpuchane S, Gashe BA. Prevalence of Salmonella in raw minced meat, raw fresh sausages and raw burger patties from retail outlets in Gaborone. Food Control, 2006; 17:207-212.

21. Ashenafi M. Microbial flora and incidence of some foodborne pathogens on fresh beef from butcher's shops in Awassa,Ethiopia. Bull Anim Hlth Prod Afr, 1994; 42:273-277.
22. Beyene G, Asrat D, Engers H, Wain J. Phenotypic and Molecular characterization of Salmonella in Ethiopia. $\mathrm{PhD}$ dissertations. Addis Ababa University, Ethiopia. 2009.

23. Collee JG, Mackie TJ. Practical Medical Microbiology. Churchill livingstone.14th ed.,1996; 883-884, 898-907.

24. Gabriel R, Estifanos, K. Nasal Carriage and Drug Sensitivity of Staphylococcus aureus among Health Workers of Jimma University Specialized Hospital, Southwestern Ethiopia. Ethiop J Health Sci. 2007; 17:73-79.

25. Muleta D, Ashenafi J. Salmonella, Shigella and growth potential of other food borne pathogens in Ethiopia street vended foods. East Africa Med J, 2001; 78(11):576-580.

26. Lin J, Yeh KS, Liu HT, Lin JH. Staphylococcus aureus isolated from pork and chicken carcasses in Taiwan: prevalence and antimicrobial susceptibility. J Food Prot, 2009; 72(3):608-11.

27. Balta B, Fetene D. Nasal carriage of methicillen resistant Staphylococcus aureus strains among inpatients of Jimma Hospital, Southwest Ethiopia. Ethiop J Health Sci, .2003; 13(2):107116. 